\title{
O papel do Estado: Um retrato da administração pública na Era Var- gas com um diálogo a partir da obra de Pedro Cezar Dutra Fonseca. "Vargas: $O$ capitalismo em construção"
}

The role of the State: A portrait of the public administration in the Vargas era with a dialogue from the work of Pedro Cezar Dutra Fonseca. "Vargas: O Capitalismo Em Construção ".

Jódiney Benedito Marques ${ }^{\dagger *}$; Eduardo Freitas da C. Silva

Como citar esse artigo. Marques, JB; Silva, EFC. O papel do Estado: Um retrato da administração pública na Era Vargas com um diálogo a partir da obra de Pedro Cezar Dutra Fonseca. "Vargas: O capitalismo em construção". Revista Mosaico. 2018 Jul./Dez.; 09 (2): 18-23.

\begin{abstract}
Resumo
A proposta do trabalho é fazer uma análise da administração pública no governo Getúlio Vargas, a partir da obra de Pedro Cezar Dutra Fonseca com ênfase nos setores econômicos, políticos, sociais e industriais. O retrato da gestão pública neste período tem como proposta, a difusão da sociedade capitalista que emergia no Brasil com consistência, e as bases sólidas advindas de outros países. As reformas contempladas no governo de Getúlio Vargas proporcionam a construção, e a dinâmica do capitalismo no país, e com isto, a sua contribuição aos setores ligados a administração pública. Também serão descritos alguns pontos ligados aos períodos presidenciais de Getúlio Vargas (1930 a 1945). Para tanto a abordagem da história econômica será indispensável para os estudos dos fatos a serem discorridos nesta etapa

Palavras-Chave: Administração Pública, história econômica, capitalismo.
\end{abstract}

\begin{abstract}
The proposal of the work is to make an analysis of the public administration in the Getúlio Vargas government, starting from the work of Pedro Cezar Dutra Fonseca with emphasis in the economic, political, social and industrial sectors. The picture of public management in this period has as its proposal the diffusion of capitalist society that emerged in Brazil with consistency and the solid foundations of other countries. The reforms contemplated in the Getúlio Vargas administration provide the construction and dynamics of capitalism in the country, and with this, its contribution to the sectors related to public administration. Some points related to the presidential periods of Getúlio Vargas (1930 to 1945) will also be described. For this, the approach of economic history will be indispensable for the studies of the facts to be discussed at this stage.

Keywords: Public Administration, economic history, capitalism.
\end{abstract}

\section{Introdução}

Este artigo tem a proposta de analisar a administração pública sob a visão da obra de Pedro Cezar Dutra Fonseca, através do diálogo do livro VARGAS: O Capitalismo em Construção. Para tanto, o objetivo é avaliar os aspectos abordados naquela época, demonstrando os meios de gestão na esfera pública federal.

A escolha da obra é dada pelo objeto de estudo tratado no livro de Fonseca, onde as suas contribuições têm grande relevância para a sociedade brasileira, e também, por ser tratar de um clássico para os estudos da história contemporânea.

De posse da obra de Fonseca pretendemos fazer uma contextualização do período Vargas, e suas fases, enquanto gestor no período de (1930 a 1945).

A metodologia utilizada será a revisão bibliográfica, leituras de livros, artigos científicos, periódicos especializados, dissertações e teses. Desta forma será possível a composição do trabalho.

Portanto, na primeira fase do trabalho tem como finalidade os anos 30 e a nova ordem: uma nova proposta no cenário mundial, e para a segunda fase é a discussão do Estado Novo e os aspectos ligados a industrialização e na terceira fase uma abordagem do Segundo governo de Vargas.

As reformas iniciadas por Vargas no campo da economia trouxeram uma consistência para o plano de urbanização e industrialização, já que o Estado foi o grande interventor destas mudanças, coma modernização e a criação de diferentes órgãos no sistema político.

O país avança, mas por enquanto não rompe drasticamente com a sua estrutura anterior, pois conforme Fonseca (1999, p.25) "as mudanças deramse sem alterar a estrutura fundiária, e a questão da

\footnotetext{
Afiliação dos autores:

$\dagger$ Mestrando do Programa de Pós-Graduação em Economia e Gestão Empresarial da Universidade Cândido Mendes (UCAM)

* Mestre pelo Programa de Pós-Graduação em Ciências Sociais da Universidade Federal de Juiz de Fora, atualmente é Técnico em Assuntos Educacionais, da Universidade Federal Fluminense, atuando no Pólo Universitário de Volta Redonda na Coordenadoria de Extensão do Instituto de Ciências Exatas e Tutor Presencial do Curso de Especialização Gestão Pública Municipal UFF - PNAP.
} 
propriedade foi mencionada apenas dentro de estreitos limites".

\section{Uma nova ordem a partir dos anos de 1930}

Para Fonseca (1999) existe grande relevância os anos 30, e por extensão, a "Revolução de 30", para a história brasileira, que trouxe consigo questões advindas na estrutura institucional no país, ou seja, uma nova forma de interpretação da questão econômica e política que se opõe a República Velha. Entretanto, Fritsch (1980a) diz que "este é um período que na história republicana, existe várias sucessões de crises econômicas, e com isto, é possível um novo redesenho das políticas econômicas, com as formas de organização do Estado".

O modelo exposto até então, na República Velha é veementemente combatido de forma a dar um novo segmento, ou seja, novos pensadores emergem com a corrente liderada pelo movimento cepalino.

Para tanto os adeptos à Comissão Econômica para a América Latina e Caribe (CEPAL), tem uma nova proposta a ser difundida, após a Revolução dos anos 30 , porém o "modelo agroexportador" dado à visão do grupo anterior aos economistas da CEPAL, não é mudado, para a ruptura e avanços da nossa economia.

Com um pensamento mais amplo e, com as influências advindas da América Latina, um grupo de pensadoresligadosàáreaeconômicaedesenvolvimentista no Brasil passa a visualizar um modelo mais amplo e dinâmico para o fortalecimento de alguns setores, que até então, ainda não tinham conseguido avançar porque o modelo de gestão pública, ainda não era suficiente para a sustentação do crescimento.

Conforme Tavares et al (1972), visualizou que a economia brasileira tinha que ter um novo "modelo", de "substituição de importações", em oposição ao modelo agroexportador do período imediatamente precedente" 1

Todavia Fonseca (1999) por meio de sua obra diverge do pensamento cepalino, pois para ele as mudanças adquiridas com a Revolução de 30 e o modelo agroexportador teriam condições de alavancar o crescimento industrial. Então o procedimento por ele adotado é contestado no que tange os meios desta condução da política industrial.

Para tanto cabe também mencionar, sem reparos, a seguinte passagem de S. Draibe (1980, p.16):

"Penso que somente nesta perspectiva histórica poder-se-á com rigor identificar a direção política do processo de transformação capitalista no Brasil. O que está em pauta são as tendências alternativas frente à industrialização e as bases sobre as quais se definem no Estado distintos projetos de transformação social e de hierarquização de interesses econômicos e políticos. Ou seja, os distintos conteúdos com que se pretendeu equacionar e resolver as grandes questões da Revolução Burguesa: a questão agrária, a questão das relações das frações burguesas entre si e com as burguesias internacionais já constituídas, a" questão social" e, finalmente, a de construção e funcionamento das próprias estruturas estatais".

Segundo Furtado (2007), no caso do Brasil, o produto que apresentava maior vantagem relativa era o café, mas com as mudanças no cenário internacional no período dos anos 30 , devido à crise mundial a commodity de exportação brasileira fica em situação vulnerável, pois a produção de café, em razão de fortes estímulos recebidos, cresceu fortemente na segunda metade desse decênio ${ }^{2}$.

Diante dos fatos apresentados em Furtado a convergência na sistematização dos dados analisados por Fonseca(1999), mas a pontos divergentes, dopensamento cepalino, pois a atividade econômica brasileira estava voltada exclusivamente para o seu produto primário de maior relevância que era o café, e com o crash da bolsa de Nova Iorque ocorreram transformações na economia Brasileira levando muitos cafeicultores a bancarrota. Com a dificuldade de exportar o produto que, então era enviado na forma bruta para o exterior e, sem ter outro comprador interessado na produção de café, a solução encontrada, pelos produtores para a elevação dos preços foi à queima dos estoques como forma de amenizar os prejuízos, e com isto agir na regulação dos estoques.

A interpretação de Vargas faz menção que a crise permitiria que, no prosseguimento do discurso, houvesse forte apelo à centralização econômica na esfera federal. O principal produto brasileiro de exportação era o que mais sentia os reflexos negativos da situação internacional e, coincidentemente, vinculava-se a ele o principal adversário político do novo regime: a oligarquia paulista. Então a 23 de novembro de 1934, em discurso que lembrava a "obra econômica da Revolução", em Porto Alegre, assim pronunciava:

\footnotetext{
"Para se verificar o efeito das medidas adotadas pelo Governo Provisório em favor da economia, basta computar os dados de 1930 com os atuais. A depressão universal iniciada em 1929 refletia-se, ameaçadoramente, sobre o café. Enfrentando sem temor a herança que nos transmitira o último governo, os dirigentes revolucionários combateram de face, os resultados desastrosos dos stocks acumulados, da superprodução, do subconsumo e degradação dos preços. Se prosseguisse o ritmo anterior, o Brasil teria, neste ano, como produto das safras de 1930 e 1934, um stock de 115 milhões de sacas de café. Pela simples enunciação destes números, poderia avaliar o destino sombrio que aguardava o povo brasileiro". Vargas, Getúlio (1938, v. 1, p.117)
}

Embora Vargas não negligenciasse o caráter internacional da crise, geralmente o deixou restrito ao setor importador e exportador, não o usando, via de regra, 
como pretexto para justificar os fracassos internos, em busca de sua legitimação ou ampliação de sua base de apoio. O simples fato de não mencionar frequentemente em seus discursos da época o aspecto internacional da crise vem corroborar esta afirmação. Esta certamente é uma das razões que levou alguns estudiosos das relações internacionais do Brasil no período a constatarem o desprezo com que Vargas tratava a política externa (pelo menos até as vésperas do Estado Novo, uma vez que, à medida que se aproximava a Segunda Guerra, é inegável sua expressão, principalmente com a barganha feita entre os Estados Unidos e o eixo para definir o alinhamento do Brasil).

É importante ressaltar que neste período de acordo com Saes e Farina (1999 p. 54-55)

\begin{abstract}
"A participação do Brasil no mercado internacional do café tem sido decrescente. No início do século XX o Brasil chegou a deter $80 \%$ do total do mercado internacional do café, na década de 90 dominava apenas $25 \%$ a $30 \%$ do mercado, tendo permanecido desde os anos 60 com a exportação praticamente estagnada em cerca de 17 milhões de sacas".
\end{abstract}

Conforme Fonseca (1999), no momento de eclosão da crise de 1929, o Brasil vivenciava mais um contexto de superprodução, abalando os programas de valorização do café, pois, ao mesmo tempo, a bolsa de Nova Iorque despencava, e, em todo mundo, muitas organizações foram fechadas. Assim, milhares de desempregados foram para as ruas e os empréstimos restringidos, uma vez que o crédito desaparecera das praças. Então, é possível verificar que os pontos mencionados são comuns, pois a temática central deste estudo é comum a todos os autores citados no texto, onde o epicentro da queda dos preços do café, mesmo em meio a uma crise é a superprodução.

A questão do crédito colocada por Fonseca é ampla, visto que alguns autores não fazem uma análise detalhada, pois à medida que reduzem os meios de financiamento da produção, a atividade econômica também diminui o que pode acarretar impactos negativos para o crescimento. Mas, neste período todo o setor brasileiro sofre com a crise, porém, o café é o que mais tinha impacto na sociedade brasileira.

\section{O Estado Novo e a Industrialização}

O Estado Novo compreende-se no período de 1937-1945, com o surgimento da figura dos decretosleis, e a perda de forças do judiciário, o autoritarismo e a repressão dominaram o quadro da época, e foram nomeados interventores para governarem os Estados.

A legislação social, apesar de suas ambiguidades, em diversos aspectos favoreceu a classe operária (ver Rodrigues, 1981). Embora seja difícil encontrar substância nas atividades dos inúmeros conselhos e autarquias que pululavam no período, a decisão de iniciar, em 1940, a construção da primeira usina siderúrgica integrada brasileira utilizando coque mineral marcou clara mudança na forma de ação do Estado.

Fonseca (1999), não deixa de relatar a questão trabalhista em prol da classe trabalhadora, ou seja, algo de bastante relevância para a obra se comparada com os demais autores, já que a gestão exercida por Vargas, em sua luta de forma incansável era manter os direitos trabalhistas dos operários. Com a presença de um novo período e, novas mudanças ocorrendo, no cenário econômico e político, não podem ser deixadas de lado, a abordagem de pontos como a ação governamental que tinha como finalidade o desenvolvimento. Então, a intervenção foi algo positivo para que o Brasil pudesse desenvolver o seu parque industrial, porque com as grandes quantias advindas do setor público em pouco tempo obras importantes estavam sendo erguidas pela capacidade de investimento.

Vargas, ao longo do Estado Novo, inúmeras vezes repetiu que o objetivo da intervenção governamental era alcançar o desenvolvimento econômico. O que mais tarde seria vagamente chamado de "ideologia desenvolvimentista"- e que reflete, em várias formas, o compromisso dos diversos governos com o desenvolvimento das forças produtivas e, mais especificamente, com a industrialização do país - teve seu aparecimento durante o Estado Novo. Então, somente a partir de 1937 este deixou de ser apenas uma ideia, ou seja, o ponto de um programa mais amplo, para tornar-se a pedra de toque de toda a ação governamental, justificando seus atos, as mudanças institucionais, o incentivo a determinados setores, a criação de determinados órgãos: com o Estado Novo, "o intervencionismo conservador" positivista paulatinamente passou a ter a cara de um intervencionismo com compromissos com o futuro" ${ }^{\text {. }}$

A questão desenvolvimentista, abordada em Fonseca (1999), para Vargas teve o seu início com Raúl Prebisch economista da Comissão Econômica para América Latina e Caribe (CEPAL), e Furtado como figuras centrais, através de um conjunto de ideias econômicas que fundamentam a retórica de uma mudança radical na trajetória de nossa evolução econômica advindo de um pensamento econômico dominante na América Latina e pós Segunda Guerra Mundial.

A construção do consenso em torno dessas ideias é fundamental para entender a mudança qualitativa que sofre o processo de industrialização no Brasil.

É importante salientar que na obra principal, Teoria geral do emprego, do juro e da moeda, publicada nos anos de 1930, Keynes coloca a ênfase na necessidade de atuação anticíclica do Estado em tempos de crise, por meio de políticas econômicas no sentindo de estimular a 
demanda. Essas políticas deveriam ter o objetivo tanto de dar condições aos investimentos se realizarem como de possibilitar ganhos no poder aquisitivo da classe trabalhadora, potenciais consumidores das mercadorias produzidas em uma economia.

"No Brasil, a influência da noção de planejamento econômico do Estado se faz sentir já nos anos de 1940. Durante a era Vargas (1930-1945), período em que se dá a reorientação no papel do Estado em nossa economia, o parque industrial brasileiro triplicou de tamanho".

Aspectos relevantes são analisados na obra de Fonseca que vão de encontro com as ideias Keynesianas, e com isto, o processo de crescimento é favorável quando o administrador público propõe mesmo, em período de crise aumentar os gastos na área pública com o propósito de uma mudança positiva e, assim, diante dos estímulos colocados a taxa de crescimento venha fomentar o processo da economia. Nas argumentações de Keynes, a análise feita por ele é que o governo tem que atuar com política fiscal expansionista, ou seja, aumento dos gastos para alavancar a economia.

Porém, é válido salientarque Fonseca (1999) busca ressaltar o motivo pelo qual, a economia brasileira teve um atraso imenso, em sua política industrial, em relação a outras economias de países ditos desenvolvidos, porque a base econômica da política realizada era primário exportador, onde a mão de obra era totalmente escrava, e os detentores do capital atuavam no sistema escravista moderno visando à especialização em uma monocultura de exportação, que durante todo o século XIX, essa commodity foi o café.

Então, com a ruptura econômica e política advinda da crise do setor cafeeiro, o processo de industrialização, agora induzido por meio de políticas tarifárias e creditícias específicas, bem como por investimentos produtivos do Estado, atingia setores estratégicos como o químico e o siderúrgico. A substituição de importações dá um passo adicional em termos de complexidade produtiva, passando de uma fase inicial em que contemplava apenas o setor de bens de consumo não duráveis (como alimentos e vestuários), para abarcar o de bens de consumo duráveis (eletrodomésticos) e de bens intermediários (insumos industriais). É dessa época que data a construção da primeira grande indústria nacional com capitais do Estado, a Companhia Siderúrgica Nacional.

Outro elemento fundamental para se entender a transição da economia brasileira de um modelo primárioexportador para um modelo desenvolvimentista industrializante, centrado na dinâmica interna de nosso mercado, consiste no surgimento, mesmo que tardio, de mecanismos de proteção social voltados à classe trabalhadora.

O nacionalismo ideológico do Estado Novo não se confundia, portanto, com a repulsa ao capital
estrangeiro.Ao dizer-senacionalista, Vargas justificava-o recorrendo a argumentos ufanistas, de exaltação à Pátria, à grandeza de seu povo e de seu futuro, ou simplesmente o confundia com a sua preocupação em fortalecer a unidade nacional, limitando a autonomia dos estados e estabelecendo a supremacia do poder federal sobre os locais ${ }^{4}$.

\section{Segundo governo de Vargas}

Período marcado por revoltas na história republicana, o segundo governo Vargas ainda divide a literatura quanto a seus traços essenciais. Embora se admitisse, na maioria das vezes, tratar-se de governo empenhado com o desenvolvimento capitalista do Brasil -e, portanto, voltado à consolidação e aprofundamento da dominação burguesa -, existem interpretações inclusive conflitantes no que diz respeito à forma pela qual procurava alcançar seus objetivos, quanto a seus reais propósitos em diversas áreas, à sua política econômica, às alianças políticas sustentadoras e opositoras ao governo e à sua ideologia. Não se pretende discutir exaustivamente a bibliografia existente, mas dela valerse no debate, buscando colaborar na interpretação do período com base na leitura dos discursos de Vargas.

Conforme Lessa e Fiori (1984), como se sabe, não chegaram a ser tão incisivos nesteaspecto, pois admitiram os compromissos desenvolvimentistas do governo no "longo prazo", postulando a presença da ortodoxia nas medidas de "curto prazo". Para tanto o sentido governamental de vencer barreiras ao desenvolvimento capitalista e consolidar o poder burguês, admitindo, como seria de esperar, que a gestão das finanças estatais não raro exigia medidas de saneamento, diante dos déficits e gargalos nas contas públicas - em geral presentes na execução de programas de crescimento acelerado. Afinal, a pretensão de crescer sem "quebrar" o aparelho do Estado, buscando fontes de financiamento adequadas a cada conjuntura, impõe-se como tarefa essencial de qualquer governo comprometido com o "desenvolvimento". Portanto, uma consulta nas diversas obras de Prebisch, sempre preocupado em buscar saídas aos empecilhos ao crescimento acelerado ${ }^{5}$.

Para Fonseca (1999) a ortodoxia marca o segundo governo de Vargas, pois com as dificuldades advindas de administrações passadas e o momento político e econômico vivenciado naquele período, algumas medidas são tomadas com a finalidade de garantir a estabilidade macroeconômica. Medidas estas que visam garantir o combate à inflação, restrição ao crédito, equilíbrio do balanço de pagamento e contenção do déficit orçamentário, argumentando que estas ocuparam realce maior em seu governo do que as questões estritamente vinculadas ao "desenvolvimento econômico". 
Entretanto, segundo Vianna (1985), Vargas não possuía qualquer pretensão de reordenar o capitalismo no Brasil e a ortodoxia fez-se presente como regra de sua política econômica. As políticas de maior envergadura, como as voltadas ao desenvolvimento econômico, constituíam-se exceções.

No caso do segundo período presidencial de Vargas, o estudo do discurso reveste-se ainda de maior importância, a ele próprio o objeto de intensa polêmica. Em geral, as questões mais debatidas são: a existência ou não de um "projeto" de governo, normalmente concebido como vinculado à industrialização, a ortodoxia da política econômica, o nacionalismo e o trabalhismo.

De posse dos fatos não podemos esquecer-nos de mostrar neste trabalho à tendência ortodoxa de Getúlio Vargas neste momento.

Sobre a relação de austeridade e desenvolvimento, vale a pena transcrever a seguinte passagem, mesmo longa, de seu discurso de 5 de julho de 1951:

\begin{abstract}
"Pôr ordem nas finanças e aproveitar bem os nossos recursos - eis a base sem a qual nada se poderá fazer no futuro. Só com a ordenação financeira poderá o Governo obter os meios necessários para a execução do vasto programa de obras públicas e sociais que é indispensável ao progresso do País e à melhoria dos níveis de vida. Com boas estradas, portos adequados e energia elétrica em abundância, será possível aumentar o número de fábricas e lavouras, conquistar novas fontes de produção e tornar mais fácil, mais barata e mais confortável a vida do povo, concretizando assim o ideal de uma melhor distribuição dos frutos do trabalho humano e das riquezas da terra entre todos os indivíduos. O problema financeiro está acima dos partidos e das paixões, pois de sua solução dependem o bem-estar, a segurança e a tranquilidade do povo brasileiro. Que o Congresso Nacional ajude, pois, o Poder Executivo a facilitar a ordem e o equilíbrio das finanças, a fim de que se abram para o Brasil novos caminhos de progresso e de expansão econômica. Não posso, em poucos meses de governo, anunciar transformações miraculosas: mas afirmo que, em todos setores, a situação melhora, e os efeitos da nova orientação irão refletir-se, fatalmente, nas condições de vida de toda a população" (Agência Nacional, 1951b).
\end{abstract}

Conforme Fonseca (1999), o debate pronunciado por Vargas, apesar de alguns membros do notório saber da sociedade Brasileira o considerá-lo ortodoxo devido aos ajustes que ele, junto com a sua equipe econômica teve que tomar naquela época, mesmo com as medidas por ele executada, o autor da obra vê-lo como um membro da heterodoxia, e isto, até hoje é foco de discussão, entre os economistas mais empenhados em superar tal dicotomia. Então, Fonseca discorda neste ponto dos demais economistas ${ }^{7}$, por entender que Vargas não estava ligado à ortodoxia. Mas as circunstâncias daquela época o levaram a um apelo de maior austeridade.

Fonseca (1999), na questão que envolve o desenvolvimento parte do pressuposto de que os discursos de Vargas permitem detectar que o objetivo principal de seu governo era o desenvolvimento econômico - mesmo quando seus pronunciamentos abordavam questões de "curto prazo". Ao tratar de problemas como inflação, concessão ou não de crédito, balanço de pagamentos, gastos públicos e tributação, suas opiniões afastam-se da ortodoxia, desviando-se do receituário dominante à época. "Então, "não se tratava da dicotomia entre "propostas desenvolvimentistas e industrializantes no longo prazo" versus" ortodoxas e restritivas no curto prazo", pois mesmo nestas é visível a heterodoxia.

Ao analisar as ideias de Vargas com a teoria de Keynes (crítica à teoria quantitativa da moeda, oferta monetária como responsável pela inflação somente após determinado nível - pleno emprego? -, influência da oferta monetária principalmente sobre o nível de renda e não sobre o de preços). Para que não gere dúvidas com os argumentos proferidos por outros autores ${ }^{8}$, Fonseca deixa claro em sua afirmação sobre, que Vargas sempre teve suas propostas ligadas ao campo heterodoxo.

\section{Considerações finais}

A exposição dialógica com a obra do autor Pedro Cezar Dutra Fonseca, vem ampliar o entendimento das questões aqui tratadas, com a finalidade de relatar os fatos da história no período Vargas, diante da administração pública vigente naquele período marcado por grandes mudanças no cenário internacional.

O país avança em áreas que até então eram desconhecidas do governo Vargas, por meio de políticas desenvolvimentistas, ou seja, neste primeiro momento a agricultura que, então era geradora de excedente passa a contribuir para o avanço da indústria.

No campo político houve algumas controvérsias nos vários momentos da gestão Vargas, que o impediram de concretizar algo maior em sua segunda passagem pela presidência, e com isto, os seus adversários conseguiram desestruturar a sua base política, ou seja, a população que era a sua grande aliada vai de forma contrária as atribuições dele na condução da política econômica.

A Revolução de 30 que atinge proporções de grande vultuosidade no cenário mundial faz com que o governo redirecione a condução da política cafeeira, ou seja, a commodity brasileira tem o seu preço mínimo por falta de compradores devido, a instabilidade mundial e, a oligarquia cafeeira que tinha no produto os seus ganhos vê os seus lucros declinarem, então o governo estabelece a aquisição do estoque como uma forma de pressionar a subida dos preços, já que a produção do café estava voltada para o mercado externo.

A gestão do governo Vargas contribuiu com o progresso da sociedade brasileira, por meio de investimentos que fomentaram o parque industrial, que em curto prazo seria uma medida para a correção de 
distorções advindas do novo cenário que acarretava a população.

\section{Notas}

1. Para ver outros autores leiam Furtado, Celso (1977b, cap. 3034), Rangel, Ignácio (1981, p.26; 1984 p.88), Singer, Paul (1984, p. 214-7), Tavares, Maria da Conceição (1972, p. 29-124), Mello, João Manuel Cardoso de (1982, p.110).

2. A produção exportável de café aumentou de 15, 761 milhões para 28, 492 milhões de sacas de sessenta quilos, segundo dados publicados pelo Instituto Brasileiro do Café. Os dados estatísticos relativos à evolução do problema cafeeiro a partir de 1925 estão reunidos em $\mathrm{O}$ desenvolvimento econômico do Brasil, Banco Nacional do Desenvolvimento Econômico.Comissão Econômica para a América Latina das Nações Unidas, segunda parte, capítulo II, anexo estatístico.

3. O intervencionismo do Estado Novo, a despeito de também poder ser tachado de conservador (em posição ao intervencionismo "social-democrata" ou "socialista"), diferida fundamentalmente do positivismo enquanto ideologia, ao abandonar o dogma do orçamento equilibrado. Entre as finanças sadias e o desenvolvimento econômico, o Estado optou francamente pelo último. O equilíbrio orçamentário e a austeridade, com isto, passaram a não existir nem na política econômica nem na retórica governamental que a justificava. Vargas, Getúlio (1940, v.6, p.53-4; v.10, p. 196; v. 5, p. 281).

4. Nacionalismo, às vezes, significa praticamente ditadura: "Profundamente nacionalista, o regime assegura e consolida a unidade nacional, faz restrições formais à autonomia dos estados, suprimindo símbolos regionais, estendendo os casos de intervenção, estabelecendo a supremacia das leis federais sobre os locais, nos casos de concorrência legislativa, atribuindo ao poder central a faculdade de requisitar, a cada momento, as milícias estaduais, etc". A passagem consta da entrevista ao Lokal Anzeiger, publicada em Berlim em 20/12/1938 e no Rio de Janeiro a 21 do mesmo mês. Ver: Vargas, Getúlio (1940, v. 6, p. 153-8).

5. Vejam-se, neste sentido, seus ensaios publicados em obra intitulada Dinâmica do desenvolvimento latino-americano (Prebisch, Raúl, 1964).

6. Vargas, Getúlio (Agência Nacional, 1951b). As citações seguintes foram daí extraídas.

7. A literatura a respeito da política econômica dos anos 30 não é consensual neste aspecto, e exatamente o que é polêmico e o que divide os autores é a questão da continuidade ou ruptura com relação à política econômica dos anos precedentes. Entre as análises que enfocam a mudança da política econômica, destaca-se a clássica interpretação de Celso Furtado. (Furtado, Celso, 1977a, cap. 31$33)$.

8. Política econômica na década de 1930. Peláez, Carlos Manuel (1972; 1971, p. 63-82)

\section{Referências Bibliográficas}

DRAIBE, Sônia M. Rumos e metamorfoses; um estudo sobre a constituição do Estado e as alternativas da industrialização no Brasil, 1930-1960. São Paulo, FFLC/USP, 1980. Tese de doutorado (datilografado).

FONSECA, Pedro Cezar Dutra. Vargas: O Capitalismo em Construção. São Paulo: Brasiliense, 1999.

FURTADO, Celso. Formação econômica do Brasil. 34 ed. - São Paulo: Companhia das Letras, 2007.

FRITSCH, Aspectos da Política Econômica no Brasil, 1906 -1914 in P. Nehaus Economia Brasileira: Uma visão histórica, Rio de Janeiro, Campus, $1980 \mathrm{a}$.

KEYNES, John Maynard. Keynes: economia. Org. por Tamás Szmrecsányi. São Paulo, Ática, 1978 (Col. Grandes Cientistas Sociais,6).

LESSA, Carlos e FIORI, José Luiz. Houve uma política nacional populista?
XII Encontro Nacional de Economia. São Paulo. ANPEC, 1984.

MELlO, João Manuel Cardoso de. O capitalismo tardio. São Paulo, Brasiliense, 1982.

. A teoria geral do emprego, do juro e da moeda. São Paulo, Abril $\overline{\text { Cultural, }} 1983$

PELÁEZ, Carlos Manuel. As consequências econômicas da ortodoxia monetária, cambial e fiscal no Brasil entre 1889 e 1945. Revista Brasileira de Economia. Rio de Janeiro, FGV, 25(3), jul. /set.1971.

PREBISCH, Raúl. Dinâmica do desenvolvimento latino-americano. Rio de Janeiro, Fundo de Cultura, 1964.

RANGEL, Ignácio. A inflação brasileira. 3. ed. São Paulo, Brasiliense, 1978.

História da dualidade brasileira. Revista de Economia Política. São Paulo, Brasiliense, 1(4): 5-34, out./dez.1981.

Dualidade e ciclo longo. Revista de Economia Política. São Paulo, Brasiliense, 4(1): 87-100. Jan./mar. 1984.

RODRIGUES, L. M., Sindicalismo e Classe Operária, in B. Fausto (ed), História Geral da Civilização Brasileira. Tomo III. O Brasil Republicano. Vol.3 Sociedade e Política (1930-1964), São Paulo, Difel, 1981.

SAES, Maria Sylvia M.; FARINA, Elizabeth Maria Mercier. Q. O agribusiness do café no Brasil. São Paulo: Milkbizz, 1999

SINGER, Paul. Desenvolvimento econômico e evolução urbana. 2. ed. São Paulo, Nacional, 1977 a.

. Desenvolvimento e crise 2. ed. Rio de Janeiro, Paz e Terra, $1977 \mathrm{~b}$.

A crise do milagre. Rio de Janeiro, Paz e Terra, 1977c.

Interpretação do Brasil: uma experiência histórica de desenvolvimento. In: Fausto, Boris, org. O Brasil republicano III. São Paulo, DIFEL, 1984. vol. 4.

TAVARES, Maria da Conceição. Da substituição de importações ao capitalismo financeiro. Rio de Janeiro, Zahar, 1972.

Acumulação de Capital e industrialização no Brasil. 2. ed. Campinas, UNICAMP, 1986

VARGAS, Getúlio. A Nova política do Brasil. Rio de Janeiro, José Olympio, 1938-1947. 11v.

As diretrizes da nova política do Brasil. Rio de Janeiro, José Olympio, 1943. $\overline{1951 \mathrm{~b} .}$

Discursos (janeiro-julho 1951). Rio de Janeiro, Agência Nacional,

VIANNA, Sérgio Besserman. A política Econômica do segundo governo Vargas. Rio de Janeiro, PUC/RJ, 1985. Dissertação de mestrado datilografada. 